\title{
AJARAN KEPEMIMPINAN NITI SASTRA DALAM SEVA NITI
}

Oleh :

\author{
Made Nugi Nugraha
}

I Made Wirahadi Kusuma

\begin{abstract}
Nitisastra is the teachings of leaders, which also means knowledge that aims to build a state both in terms of governance, governance and community governance. In connection with the development of the state, government and society based on Nitisastra, the teachings of Hinduism can provide moral values from the form of development. In this case Nitisastra can mean a conception of governance and development of the state in general that is universal and theoretical, but has practical values. Seva Niti means leadership that serves, who provides services, gives satisfaction to those who are served, as leaders with patience and love leading organizations and followers to achieve organizational goals and the welfare of their followers. The results of this article are where we are taught how to be a leader, add insight, how to become a leader and how leaders themselves should learn more about becoming leaders of ourselves and leading people around us.
\end{abstract}

Kata Kunci: leaders and seva niti

\section{PENDAHULUAN}

Nitisastra merupakan ajaran pemimpin,yang juga diartikan ilmu yang bertujuan untuk membangun suatu megara baik dari segi tata negara,tata pemerintahan maupun tata masyarakatnya. Sehubungan dengan pembangunan negara,pemerintahan dan masyarakat berdasarkan Nitisastra,ajaran agama Hindu dapat memberikan nilai-nilai morildari wujud pembangunan tersebut. Dalam hal ini Nitisastra dapat berarti suatu konsepsi penataan pemerintahan dan pembangunan negara secara umum yang bersifat universal dan teoritis, namun memiliki nilai-nilai praktis.

Nitisastra memiliki peran dan fungsi yang sangat penting bagi umat manusiauntuk memantapkan pengalaman hidup berbangsa dan bernegara,seperti NKRI yang berlandaskan pancasila. Nitisastra mengajarkan umatnya untuk selalu ikut serta dalam pembinaan negara dan bertanggung jawab dalam mewujudkan keselamatan negara dan tujuan negara. Nitisastra 
dapat juga dipergunakan untuk membuat rumus kembali, mengakulturasi suatu konsep dengan konsep yang lainya sehingga memperoleh suatu konsep baru yang mengantarkan untuk berpandangan jauh kedepan. Berbuat dan berpikir tentang keselamatan negara dimasa lampau,sekarang dan yang akan datang merupakan bukti umat hindu peduli melaksanakan dharma agama. Negara adalah wadah bagi setiap pemimpin untuk melaksanakan kepemimpinanya. Sehubungan dengan keberadaan negara,pemimpin dan kepemimpinan, didalam kitab Manawa Dharmasastra kita temukan petunjuk sebagai berikut:

\section{Brahman praptena samskaram ksatriyena yatha widhi, sarwasyasya yathanyayan kartawyam pariraksanam}

(Manawa Dharmasastra, VII.3)

Terjemahan: Ksatria (Pemimpin) yang telah menerima sakramen menurut Weda, berkewajiban melindungi seluruh dunia dengan sebaikbaiknya.

Agama Hindu tidak memebenarkan seorang pemimpin negara menjadikan kesibukan sebagai alasan untuk tidak memberikan perhatian pada pembinaan pribadinya secara fisik atau mental,dan juga terhadap keluaganya.Seperti contoh dalam karya sastra kekawin Ramayana mengisahkan seorang raja termasyur yang bernama "Sang Dasaratha". Di dalam kekawin Ramayana, I.3 menyebutkan sebagai berikut :
Guna manta Sang Dasaratha, wruh sira ring weda bhaktiring dewa, tar malupeng pitra puja, masih ta sireng swagotra kabeh.

\section{Terjemahan:}

Sangat utama beliau Sang Dasaratha, Sri Baginda ahli weda (ilmu pengetahuan) Dan sujud bhakti kehadapan Ida Sang Hyang Widhi,tidaklahlupa beliau melaksanakan pemujaan terhadap leluhurnya, Sri Baginda sangat mencintai keluarganya dan masyarakatnya.

\section{PEMBAHASAN}

\subsection{Ajaran kepemimpinan Seva Niti}

Seva dalam bahasa sanskerta berarti: to serve, melayani (Shastri and Pandey, 2007). Niti dalam bahasa sanskerta berarti membimbing ke arah yang baik, moralitas dan etika (Harshananda, 2008). Niti berarti memimpin, bertindak benar, etika, moral yang baik. Seva Niti berarti kepemimpinan yang melayani, yang memberikan pelayanan, memberikan kepuasan kepada yang dilayani, sebagai pemimpin dengan penuh sabar dan kasih memimpin organisasi dan pengikutnya untuk mencapai tujuan organisasi dan kesejahteraan pengikutnya.

Kepemimpinan berasal dari kata pemimpin, yang berarti orang yang memimpin kepemimpinan berasasl dari kata "Pimpin" yang diberi Awalan ke dan akhiran an dalam 
kepemimpinan menunjukkan kata sifat tentang pemimpin. Posner (2004: 13) mengatakan bahwa kepemimpinan sama sekali bukan tentang kepribadian seseorang, melainkan tentang praktik memimpin. Praktik memimpin dalam kepemimpinan yang dijelaskan oleh Posner, yaitu bagaimana tentang: mencontohkan caranya', menginspirasi visi bersama; menantang pro ses; memungkinkan orang lain bertindak; menyemangati jiwa.

Kepemimpinan sangat berhubungan erat dengan kekuasaan, pemaksaan dan manajemen. Burns (1978) dalam Northouse (2013:12) menjelaskan bahwa kekuasaan dipandang dari sudut hubungan, bukan suatu hal yang digunakan kcpada orang lain untuk mencapai tujuan mereka sendiri, tetapi kekuasaan terjadi di dalam hubungan antarmanusia. Hal itu seharusnya digunakan oleh pemimpin dan pengikut guna mencapai tujuan mereka. Northouse (2013:12) menjelaskan tentang pemaksaan dan manajemen yang digunakan oleh pemimpin, pemimpin bisa menggunakan pemaksaan untuk mencapai tuj uan. Kepemimpinan yang memaksa tidak digunakan sebagai kepemimpinan ideal, karené bertujuan untuk mencapai tujuannya sendiri dan jarang tertarik dengan kebutuhan serta keinginan pengikutnya. Pemimpin tidak akan bisa bekelja sama dengan pengikutnya untuk mencapai tujuan dengan menggunakan pemaksaan. Kepemimpinan dan manajemen memiliki konsep yang jelas. Manajemen berarti melakukan aktivitas dan menguasai rutinitas, memimpin berarti memengaruhi orang lain dan menciptakan visi untuk berubah. Bennis dan Nanus (1985) dalam Northouse (2013: 13) mengatakan bahwa, manajer adalah orang yang melakukan segala sesuatu dengan benar, sementara pemimpin adalah orang yang melakukan hal \$338 bum Manajemen dan kepemimpinan sangatlah penting bila organisasi mahnur. K011“ (1990) dalam Nonhouse (2013: 12) memberikan contoh dimana organisasi memiliki menejemen yang kuat tanpa kepemimpinan akan bersifat menghambat dan birokratis, sebaliknya kepemimpinan tanpa manajemen yang baik akan menghasilkan pembahan yang keliru dm tidak hermakna . Agar efektif, organisasi perlu memupuk menajemen yang baik.

\subsection{Seva Niti dalam Bhagawad Gita}

Bhagawad Gita adalah ajaran yang ndirumuskan oleh Sri Krisna untuk laki-laki dan perempuan yang bekerja yang terlibat secara aktif dalam berbagai bidang pekerjaan sebagai staff atau pemimpin dalam organisasi, bukan untuk mereka yang pergi ke hutan sebagai wanaprastha atau hidup mengembara sebagai sanyasi. Ajaran rahasia untuk bisa bekerja secara efektif dalam Bhagawad Gita adalah sthitaprajna (kebijaksanaan yang mantap), lokasamgraha (untuk kesejahteraan masyarakat luas), jnana (ilmu pengetahuan). Sthitaprajna muncul dari pikiran yang tenang, yang menghasilkan kebijaksanaan yang mantap. Kerja yang dilakukan tanpa pengetahuan hanya akan membawa kegagalan. Ilmu pengetahuan yang tidak dipraktikan dalam kerja adalah kegagalan yang lebih besar. Untuk bisa mewujudkan 
masyarakat yang sejahtera, seorang pemimpin haruslah membuang sifat mementingkan dirinya dirinya sendiri (ahamkara) dengan menumbuhkan cinta kasih menjadi tat twam asi, merasakan aku adalah engkau.

Lokasamgraha adalah visi pemimpin Hindu untuk menjadikan masyarakatnya cinta damai, menghindari peperangan, memelihara kesejahteraan masyarakat, menjaga keseimbangan pembangunan, membangun masyarakat dan meningkatkan partisipasi masyarakat, menggali dan mengalokasikan segala sumber daya untuk tujuan pembangunan dan kesejahteraan masyarakat, meningkatkan toleransi, cinta kasih dan persaudaraan antar sesama warga di dalam masyarakat. Dengan cara demikian lokasamgraha bisa diwujudkan di dalam masyarakat.

Yajna dalam seva niti adaalah bekerja sebagai korban suci, yang merupakan ibadah, yang sifatnya sakral, suci, sehingga harus dihornati dan didahulukan sebagai suatu yang sangat utama dalam hidup. Bekerja sebagai yajna berarti bekerja untuk dipersembahkan kepada Tuhan. Oleh karena itu filosofi dalam bekerja haruslah suci, bersih, damai, indah, memberikan kebaikan. Selanjutnya, Tapa dalam seva niti berarti semangat bekerja, terus menjaga semangat dalam bentuk panas yang ada di dalam pikiran/hati agar terus hidup, sehingga usaha untuk mewujudkan visi bisa dilakukan tanpa kenal lelah. Untuk menghidupkan semangat, pemimpin harus terus menerus membersihkan pikirannya dengan disiplin diri dengan bekerja dan berdoa. Sedangkan Dana berrati sesuatu, berupa barang, uang, bantuan, dukungan, kepada orang yang membutuhkannya dengan ikhlas. Tugas pemimpin adalah memberi dalam bentuk materi dan non materi. Memberi artinya menyalurkan, mentribusikan, mengalokaasikan dana yang tepat sasaran untuk kesejahteran masyarakat. Pemimpin harus memiliki sifat murah hati, tidak pelit, untuk masyarakat, bukan untuk diri sendiri. Dalam Bhagavad Gita XVII.5 menjelaskan bahwa kegiatan yang dilakukan oleh orang bijaksana dalam bentuk yajna (berkurban), dana (bersedekah), tapa (tenang, fokus pada tujuan, semangat) adalah merupakan suatu tindakan penyucian diri. Bhagavad Gita XVII.25 juga menegaskan bahwa yajna, tapa, dan dana yang dilakukan dengan okhlas adalah usaha yang dilakukan untuk tujuan pembebasan (moksa).

Seva niti melakukan yajna (berkorban suci), dana (pemberian ikhlas dalam bentuk materi dan non materi), tapa (tenang, fokus, semangat) dalam menjaga hati dan pikirannya untuk tetap tenang, fokua dan semangat untuk mencapai tujuan organisasi. Tugas pemimpin adalah melakukan yajna, dana, dan tapa, yaitu bekerja, memberi dan tetap bersemangat dalam usaha memajukan organisasi dan masyarakat. Tugas tersebut dilaksanakan berdasarkan srada dan bhakti (keimanan dan penyembuhan) kepada Tuhan, dengan bekerja tanpa pamrih, tanpa kepentingan pribadi, bahwa segala tujuan dan hasil kerja dipersembahkan kepada Tuhan dan untuk kesejahteraan masyarakat. Jika tugas pemimpin yang suci tersebut tidak dilaksanakan, bukan untuk tujuan yajna, tapi untuk kepentingan 
pribadi (diri sendiri), keluarga dan kerabatnya, maka sesungguhnya pemimpin tersebut adalah pencuri, diibaratkan sebagai orang yang memasak makanan bagi dirinya sendiri. Pemimpin yang telah mendapatkan kesenangan/kenikmatan dari fasilitas dan pengaruh kepemimpinannya adalah pemimpin yang tidak bekerja berdasarkan srada dan bhakti, dia adalah pencuri.

\subsection{Seva Niti dalam Niti Sastra}

Niti Sastra adalah sebuah pustaka yang berisi pemikiran-pemikiran tinggi tentang moralitas, pergaulan sehari-hari, dan tentang bhakti kepada Tuhan Yang Maha Esa (Sri Hari, dalam Darmayasa, 2014 : XV). Niti Sastra adalah didactic poem atau upadesa kavya, yaitu karya sastra yang bersifat mendidik, bukan sebagai ilmu politik atau ilmu pemerintahan. Niti Sastra berasal dari kata Niti dan ktin yang artinya to lead, memimpin, membimbing, mendidik orang bagaimana bergaul dan bertindak setiap hari terhadap diri sendiri, binatang, tumbuhtumbuhan, manusia, bagaimana bergaul dengan orang yang lebih tua/ tinggi, sebaya, atau kepada orang yang lebih rendah/ kecil dan bagaimana mengembangkan cinta kasih kepada Tuhan Yang Maha Esa. Niti berarti dengan cara apa dibimbing, artinya dengan ajaran-ajarannya orang-orang dibimbing ke arah kebaikan, jalan terang, ke arah cinta bhakti kepada Tuhan Yang Maha Esa.Niti Sastra terdiri dari 17 Bab dan 340 sloka (Darmayasa, 2014 : xix).

Seva Niti dalam Niti sastra dijelaskan dalam bab V1: sloka 15 s/d 22, Sebagai kunci sukses bagi setiap orang yang memiliki sifat- sifat/ prinsip pemimpin dengan belajar dari sifat-sifat binatang. Sifat-sifat binatang yang dipelajari tersebut adalah sifat singa, burung bangau, ayam jantan, burung gagak, anjing, keledai. Niti Sastra menjelaskan bahwa;

Simhadekam bakadekam siksaccatvari kukkutat,

Vayasatpamcasiksecca sat sunastrini gardabhat.

(Niti Sastra VI:15)

\section{Terjemahan :}

Pelajarilah: satu hal dari singa, satu hal dari burung bangau, empat hal dari ayam jantan, lima sifat dari burung gagak, enam sifat dari anjing, dan tiga sifat dari keledai. Mereka yang mempraktikkan keduapuluh sifat tersebut di atas, akan selalu berhasil dalam setiap pekerjaan yang dilakukannya

a. Labha karya (bekerja Tuntas).

Labha karya berarti bekerja tuntas. Bekerja tuntas adalah kunci keberhasilan. Mereka yang tidak berhasil pastilah bekerja setengah hati, atau tidak menyelesaikan pekerjaan. Bekerja tuntas artinya bekerja sepenuh hati, disiplin, detil, selesai, tanpa menyisakan masalah Labda Karya berarti kerja keras, kerja cerdaas, kerja ikhlas, kerja berkualitas, kerja tuntas. Lawan dari bekerja tuntas adalah bekerja setengahsetengah, dengan hati ragu, malas dan tidak disiplin, pekerjaan yang dilakukan tidak akana selesai, pasti meninggalkan masalah, dan menghasilkan kegagalan. Seva niti harus belajar 
dari singa yang bekerja secara tuntas, sehingga dia bisa menjadi contoh bagi pengikutnya agar bisa bekerja sepenuh hati, detil dan tuntas. Labda karya adalah etos kerja yang dimiliki oleh pemimpin untuk bekerja sempurna, yaitu kerja keras, kerja ikhlas, kerja berkualitasa, kerja tuntas. Seva niti memberikan Sabda Karya kepada masyarakat dan mempersembahkannya kepada tuhan. Niti sastra menjelaskan sebagai berikut.

\section{Prabhutam karyamalpam va yannarah kartumicchati, \\ Sarvarambhena tatkarya simhadekam pracaksate.}

( Niti Sastra VI:16)

\section{Terjemahan :}

Pekerjaan yang dilakukan, apakah itu besar atau kecil dilakukan degan sepenuh hati sampai selesai. Inilah satu sifat yang harus dipelajari dari seekor singa.

Seva Niti dalam Niti sastra dijelaskan dalam bab V1: sloka 15 s/d 22, Sebagai kunci sukses bagi setiap orang yang memiliki sifatsifat/ prinsip pemimpin dengan belajar dari sifat-sifat binatang. Sifat-sifat binatang yang dipelajari tersebut adalah sifat singa, burung bangau, ayam jantan, burung gagak, anjing, keledai. Niti Sastra menjelaskan bahwa;

Simhadekam bakadekam siksaccatvari kukkutat,

Vayasatpamcasiksecca sat sunastrini gardabhat.
(Niti Sastra VI:15)

\section{Terjemahan :}

Pelajarilah: satu hal dari singa, satu hal dari burung bangau, empat hal dari ayam jantan, lima sifat dari burung gagak, enam sifat dari anjing, dan tiga sifat dari keledai. Mereka yang mempraktikkan keduapuluh sifat tersebut di atas, akan selalu berhasil dalam setiap pekerjaan yang dilakukannya.

Bekerja tuntas adalah kunci keberhasilan. Mereka yang tidak berhasil pastilah bekerja setengah hati, atau tidak menyelesaikan pekerjaan. Bekerja tuntas artinya bekerja sepenuh hati, disiplin, detil, selesai, tanpa menyisakan masalah Labda Karya berarti kerja keras, kerja cerdaas, kerja ikhlas, kerja berkualitas, kerja tuntas.

b. Dhyana Pradnya (Fokus dan Bijaksana).

Pemimpin seva niti harus mampu bekerja fokus dan bijaksana. Bekerja fokus artinya pikirannya tidak bercabang memikirkan halhal lain selain pekerjaannya, untuk tujuan memajukan diri, organisasi dan masyarakamya. Pemimpin yang bekerja fokus akan mampu membedakan hal-hal yang berhubungan atau tidak berhubungan dengan pekerjaannya; membedakan hal-hal yang penting dan yang tidak penting; melihat dan memperhatikan hal-hal yang kecil dan juga hal-hal yang besar yang bisa mempengaruhi diri, organisasi dan masyarakamya; melihat tantangan dan peluang dalam setiap kesempatan, serta mampu 
melakukan hal-hal yang perlu dan seharusnya dilakukan dalam suatu kesempatan secara tepat dan cepat. Kebijaksanaan pemimpin dalam bekerja didapatkan dari kemampuannya dalam bekerja fokus, dengan melatih keseimbangan batinnya. Niti sastra menjelaskan sebagai berikut

Indriyanica samyamyabakavatoandito narah

Desakalam balam jnatva sarwakaryani sadhayet.

(Nitisastra VI:17)

\section{Tarjemahan :}

Orang bijaksana hendaknya menahan keinginan indria-indrianya seperti burung bangau, yang setelah mengetahui dengan tepat tempat, waktu dan kekuatan barulah pekerjaan dilakukan.

c. Wirya (Disiplin, Berani dan Bertanggung Jawab)

Seva Niti adalah pemimpin yang bekerja dengan disiplin, berani dan bertanggung jawab. Disiplin artinya tepat waktu, tepat target, terjadwal, semangat. Pemimpin yang disiplin memiliki kesehatan fisik dan mental yang prima. Pemimpin yang disiplin menghargai dan mengelola orang, waktu, uang, energi dan sumber daya yang dimilikinya dengan baik. Pemimpin yang berani adalah pemimpin yang bertanggung jawab. Keberanian dan tanggung jawab menjadi suatu kesatuan. Seorang yang berani adalah dia yang bertanggung jawab. Seorang yang tidak bertanggung jawab adalah dia yang tidak berani. Tanggung jawab terhadap suatu tugas itulah yang memberikan keberanian. Seseorang mau bertanggung jawab karena dia mengerti tugasnya. Seseorang merasa bemilai karena menyelesaikan tugasnya dengan baik, yang merupakan pengabdian, pclayanan terhadap suatu tugas yang harus dikerjakannya, yang dibebankan kcpada dirinya. Orang yang bekcrja disiplin, berani dan bertanggung jawab itu adalah orang yang mandiri. Niti sastra menjelaskan sebagai berikut :

\section{Pratyutthanananca} yuddhanca samvibhaganca bandhusu Svayamakramya bhogam ca siksecccatvari kukkutat.

(Niti Sastra VI:18)

\section{Terjemahan:}

Bangun tepat pada waktunya, dengan gagah berani berhadap-hadapan bonanpur, segala sesuatu dibagi adil kepada keluarga dan makanan didapat atas usaha sendiri. Inilah empat sifat yang patut dipelajari dari ayam jantan.

\section{d. Jagra (Hati-Hati dan Waspada)}

Pemimpin seva niti adalah pemimpin yang hati-hati dan waspada dalam segala hal. Dia tidak pernah lengah, tidak pernah lepas dari kehati-hatian dan kewaspadaan. Orang yang hati-hati dan waspada adalah orang yang selalu sadar akan segala tindakan dan risiko yang akan dihadapi dari hasil tindakannya tersebut. Hatihati dan waspada bukan berarti takut, tetapi 
penuh perhitungan dengan segala keadaan dan risiko yang harus dihadapi untuk mencapai tujuan. hati-hati berani menjaga rahasia, efektif dan efisien dalam mengelola sumber daya, teliti detil, cermat dan terampil dalam bekerja, tidak cepat percaya terhadap seseorang atau sesuatu hal, selalu mencari sumber data yang benar, atau mengecek kebenaranya sebelum mempercayai sesuatu. Seseorang berhati-hati karena waspada terhadap segala kemungkinan bisa saja terjadi termasuk kemungkinan di luar perhitungan/ mendadak. Niti sastra menjelaskan sebagai berikut :

\section{Gudha maituna cahtvam kale calayasamgraham, \\ Apramadama visvasam panca siksecca vayasat.}

( Niti sastra VI:19)

\section{Terjemahan :}

Hubungan suami istri dilakukan di tempat tersembunyi,dalam setiap keadaan selalu waspada, setiap waktu mengumpulkan sesuatu yang diperlukan. melakukan setiap pekerjaan dengan amat hati hati, tidak cepat percaya kepada siapapun, pelajarilah kelima sifat ini dari burung gagak.

\section{e. Prasaja (Sederhana dan Setia).}

Seva Niti adalah pemimpin yang sederhana dan setia. Pemimpin memiliki hak untuk menikmati fasilitas kepemimpinannya, tetapi pemimpin harus tetap scdexhana, dengan menj aga penampilan fisik dan asesoris yang sederhana tetapi megah. Kesederhanaan sikap dan tingkah lakunya mencerminkan kebijaksanaan, wawasan dan pengalaman hidup yang luas. Pemimpin yang hidup dalam kcmewahan akan cepat sakit karena banyak makan, gaya hidup dan pola hidup yang tidak sehat. Pemimpin yang hidup dalam kemewahan akan cepat bangkrut karna biaya hidupnya yang tinggi, karena pengeluarannya lebih besar dari pcmasukannya. Pemimpin yang setia berarti jujur dan tulus, bersedia membela mereka yang telah benjasa dalam hidupnya, dan siap melunasi segala janji atall hutang yang telah dilakukannya. Niti sastra menj elaskan tentang kesederhanaan dan kesetiaan sebagaiberikut :

Teremahannya : Kuat menahan keinginan untuk makan banyak, makan sedikit saja sudah puas, tidur nyenyak, kalau ada sesuatu cepat terj aga, setia kepada orang Yang memeliharanya dan memiliki keberanian yang mengagumkan. Keenam sifat ini perlu dipelajari dari anjing (Niti Sastra VI: 20).

\section{f. Santhi (Puas dan Damai)}

Seva Niti adalah pemimpin yang selalu merasakan rasa puas dan damai, Puas berarti bersyukur, bahagia, menikmati segala hasil dan jerih payah yang telah dilakukan. Hati yang gembira adalah wujud dari kepuasan. Karena merasa puas smeorang menjadi gembira. Orang yang bekerja dengan hati yang gembira tidak akan merasakan keletihan atau kejenuhan. Seseorang merasakan puas karena bersyukur, menikmati kerja. Dengan hati yang bergembira, 
segala masalah di dalam bekerja, berat atau ringan, panas atau dingin, akan dinikmatinya dengan senang hati. Bekerja dengan hati yang gembira akan memberikan kedamaian lahir dan batin. Kepuasan, kegembiraan dan kedamaian dalam bekerja akan memberikan hasil kerja yang gemilang. Niti Sastra menjelaskan sebagai berikut:

Susranto pi vahed bharam sitosne na ca pasyati,

Santuastasvarate nityam trini siksecca gardabhat.

(Niti Sastra VI:21)

\section{Terjemahan:}

Walau merasa payah sekali tetapi bebannya masih tetap dibaawa, tidak melihat suasana panas atau dingin,senantiasa berjalan dengan rasa puas dan damai. Pelajarilah ketiga sifat ini dari keledai.

\section{KESIMPULAN}

Nitisastra merupakan ajaran pemimpin,yang juga diartikan ilmu yang bertujuan untuk membangun suatu megara baik dari segi tata negara,tata pemerintahan maupun tata masyarakatnya. Sehubungan dengan pembangunan negara,pemerintahan dan masyarakat berdasarkan Nitisastra,ajaran agama Hindu dapat memberikan nilai-nilai morildari wujud pembangunan tersebut. Dalam hal ini Nitisastra dapat berarti suatu konsepsi penataan pemerintahan dan pembangunan negara secara umum yang bersifat universal dan teoritis, namun memiliki nilai-nilai praktis.

Seva Niti berarti kepemimpinan yang melayani, yang memberikan pelayanan, memberikan kepuasan kepada yang dilayani, sebagai pemimpin dengan penuh sabar dan kasih memimpin organisasi dan pengikutnya untuk mencapai tujuan organisasi dan kesejahteraan pengikutnya. Bhagawad Gita adalah ajaran yang ndirumuskan oleh Sri Krisna untuk lakilaki dan perempuan yang bekerja yang terlibat secara aktif dalam berbagai bidang pekerjaan sebagai staff atau pemimpin dalam organisasi, bukan untuk mereka yang pergi ke hutan sebagai wanaprastha atau hidup mengembara sebagai sanyasi. Ajaran rahasia untuk bisa bekerja secara efektif dalam Bhagawad Gita adalah sthitaprajna (kebijaksanaan yang mantap), lokasamgraha (untuk kesejahteraan masyarakat luas), jnana (ilmu pengetahuan). Sthitaprajna muncul dari pikiran yang tenang, yang menghasilkan kebijaksanaan yang mantap.

\section{DAFTAR PUSTAKA}

Darmayasa, 2014. Canakya Niti Sastra. Surabaya: Paramita.

Miswanto, 2015. Kekawin Niti Sastra Text, Terjemahan dan komentar. Surabaya:Paramita.

Meyer, J., 2008. Pemimpin yang Sedang Dibentuk, Hal-hal Penting Untuk Menjadi Seorang Pemimpin yang Berkenan di Hati Allah. Jakarta: Immanuel Publishing House.

Northouse,P.G. , 2013. Kepemimpinan, Teori 
dan Praktek. Jakarta: PT. Indeks.

Suhardhana, K.M. 2008. Nitisastra ilmu Kepemimpinan dan Management Berdasarkan Agama Hindu. Surabaya: Paramita.

Wididana. 2019. Seva Niti Dalam Kepemimpinan gubernur Bali Periode 2008-2018. IHDN Denpasar. 